\title{
Raman investigation of corrosion products on Roman copper- based artefacts
}

\author{
Leila Es Sebar ${ }^{1}$, Leonardo lannucci ${ }^{1}$, Yuval Goren ${ }^{2}$, Peter Fabian ${ }^{2}$, Emma Angelini ${ }^{1}$, Sabrina Grassini ${ }^{1}$ \\ ${ }^{1}$ Department of Applied Science and Technology, Politecnico di Torino, Torino, Italy \\ ${ }^{2}$ Department of Bible, Archaeology and Ancient Near East, Ben Gurion University of the Negev, Beer-Sheva, Israel
}

\begin{abstract}
This paper illustrates a case study related to the characterisation of corrosion products present on recently excavated artefacts. The archaeological findings, from the Rakafot 54 site (Beer-Sheva, Israel), consist of 23 coins and a pendant, all dating back to the Roman period. Raman spectroscopy was used to identify the corrosion products that compose the patina covering the objects. To facilitate and support their identification, spectra were then processed using principal components analysis. This chemometric technique allowed the identification of two main compounds, classified as atacamite and clinoatacamite, which formed the main components of the patinas. The results of this investigation can help in assessing the conservation state of artefacts and defining the correct restoration strategy.
\end{abstract}

Section: RESEARCH PAPER

Keywords: Raman spectroscopy; PCA; corrosion; archaeological artefacts

Citation: Leila Es Sebar, Leonardo lannucci, Yuval Goren, Peter Fabian, Emma Angelini, Sabrina Grassini, Raman investigation of corrosion products on Roman copper-based artefacts, Acta IMEKO, vol. 10, no. 1, article 17, March 2021, identifier: IMEKO-ACTA-10 (2021)-01-17

Editor: Carlo Carobbi, University of Florence, Italy

Received May 7, 2020; In final form August 5, 2020; Published March 2021

Copyright: This is an open-access article distributed under the terms of the Creative Commons Attribution 3.0 License, which permits unrestricted use, distribution, and reproduction in any medium, provided the original author and source are credited.

Funding: This work was supported by the Project for the Internationalisation of Research of the Politecnico di Torino (Italy) in cooperation with the Ben Gurion University of the Negev (Israel).

Corresponding author: Leonardo lannucci, e-mail: leonardo.iannucci@polito.it

\section{INTRODUCTION}

Alloy chemical composition, microstructural features and corrosion layer stratification provide archaeologists, researchers and conservators with the scientific evidence necessary for the dating, authentication and identification of archaeological metal findings. Thus, the understanding of the complex corrosion mechanisms occurring on copper $(\mathrm{Cu})$-based alloys during burial is a fundamental prerequisite for their long-lasting conservation and safeguarding.

The corrosion of $\mathrm{Cu}$-based archaeological artefacts buried in soil for long periods depends on many variables related to the microclimatic conditions and soil chemical-physical properties. In fact, soil is a very complex environment and many different parameters, such as geological and hydrological factors and soil chemical composition, can affect the degradation mechanisms of the objects. The formation of patinas during burial can be ascribed to oxygen and carbon dioxide, moisture content, temperature, $\mathrm{pH}$ and salt content [1], [2]. Moreover, water in the soil acts as an electrolyte on the surface of the buried object, and, in the case of $\mathrm{Cu}$-based artefacts, a minimum $\mathrm{pH}$ value is required to induce the formation of stable corrosion product layers [3].

A precipitation-dissolution mechanism forms part of the degradation process, which can be explained by considering the dissolution of copper, which is kinetically controlled by the mass transport of this element from the alloy to the environment, and the diffusion of the aggressive ions towards the alloy interphase. Anionic control, in the presence of chloride ions, produces higher volume change and less coherent corrosion layers, whereas cationic processes arise in the diffusion of metallic components and become the rate-determining step, resulting in compact corrosion layers [4], [5].

Due to the complexity of both the patina structure and the degradation mechanisms, several analytical techniques and statistical data analyses are employed to collect reliable information on Cu-based artefacts. Among them, Raman spectroscopy has found a wide application in the cultural heritage field because it is non-destructive and allows measurements to be performed in situ using portable instrumentation [6], [7]. In the last decades, different studies have analysed Raman spectra acquired from copper minerals, providing important knowledge to characterise patinas related to copper corrosion [8], [9]. This 
has allowed researchers to use Raman spectroscopy in different investigations in order to identify the compounds present in the patinas of archaeological findings [10]-[11][12]. This kind of study has great relevance for assessing the artefacts' conservation state and, thus, proposing the most appropriate restoration strategy [13].

An additional tool that is often used by researchers involved in spectrometric analyses is multivariate statistics and, in particular, principal components analysis (PCA). This chemometric technique allows the user to find characteristic patterns in the acquired spectra and, therefore, to discriminate between the different components that belong to the system under study. It is possible to find various case studies in the literature that have taken advantage of this technique in different contexts [14]-[16].

This study deals with a non-invasive Raman investigation on bronze artefacts from the Rakafot 54 archaeological site in Israel. The proposed measuring approach is appropriate as a preliminary investigation, which could be performed in the field, to collect information about the stability and the conservation state of the artefacts immediately after excavation, thus leading to the development of tailored preservation strategies for the storage of these items.

In section 2, details of the Israeli bronze artefacts and the experimental methodology are presented, together with the model for PCA analysis and data matrix decomposition. Section
3 deals with the presentation and discussion of the results of the Raman spectroscopy measurements and the PCA data processing. Finally, in the concluding section, the major achievements are summarised.

\section{MATERIALS AND METHODS}

In this section, the archaeological artefacts under investigation are described as well as the main methodological issues and the data analysis performed.

\subsection{Archaeological artefacts under study}

The artefacts that are the subject of this study were excavated in the Rakafot 54 archaeological site near Beer-Sheva, Israel, close to the border between Judea and Nabataea, involving a settlement dating back to the Roman period. The site dates from the first century AD (Second Temple) to the Bar Kochba revolt against Rome in 135 AD.

The excavations were carried out by Peter Fabian, Department of Bible, Archaeology and Ancient Near East, Ben Gurion University of the Negev (Beer-Sheva, Israel), and Daniel Varga, Israel Antiquities Authority.

During the excavation, several artefacts and dozens of bronze coins were found, most of them belonging to the Roman procurators' period (6-66 AD). Of these, a set of 24 artefacts, 23 coins and a pendant were selected for the investigation of the

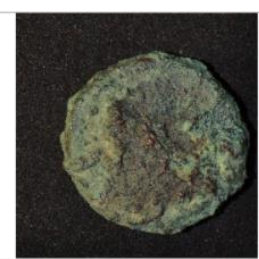

6015

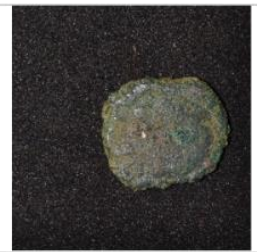

6151

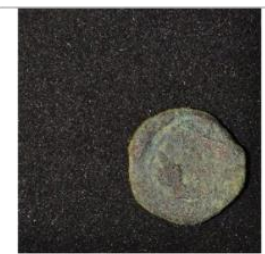

8591

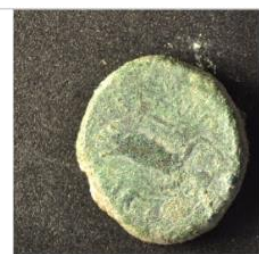

8893

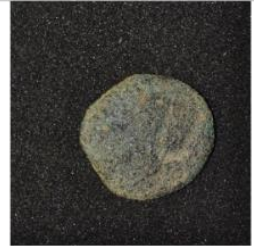

6021

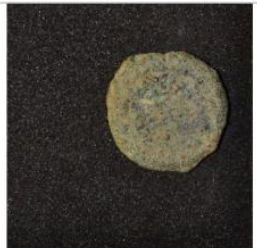

8054

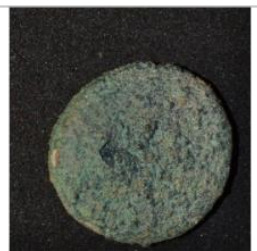

8599

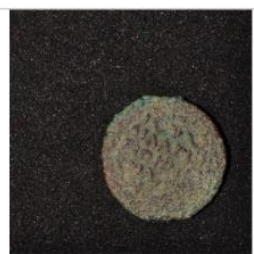

9024

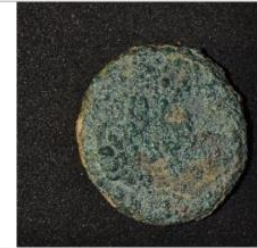

6058

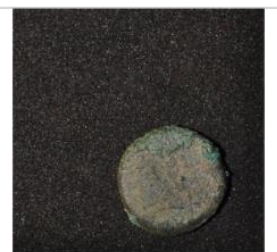

8103

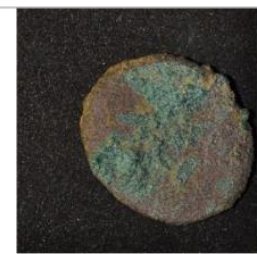

8603

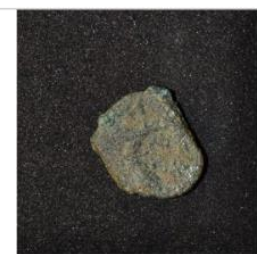

9483

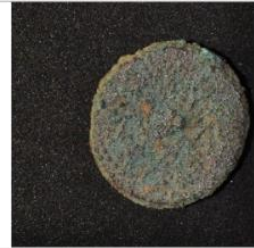

6059

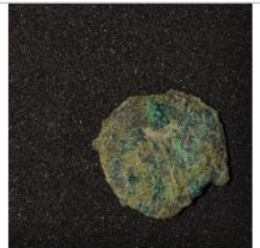

8260

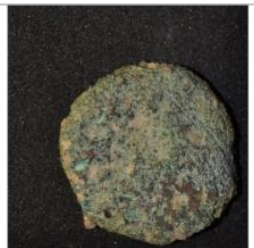

8764

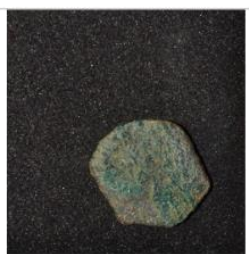

9803

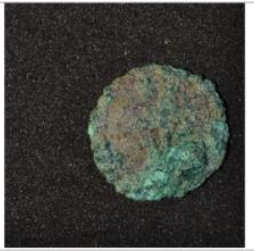

6081

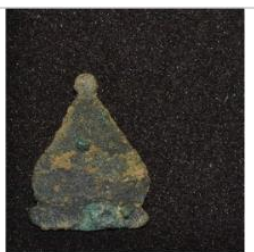

8261

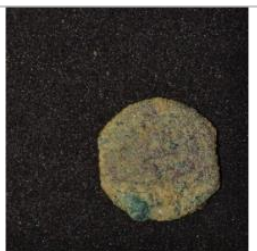

8891

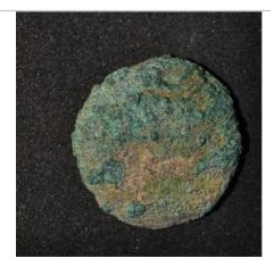

9830

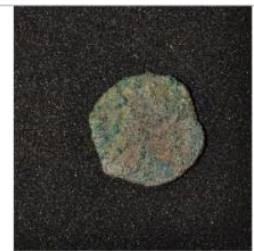

6101

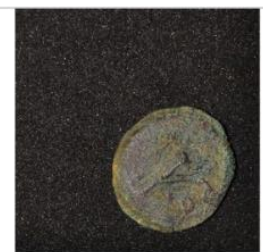

8299

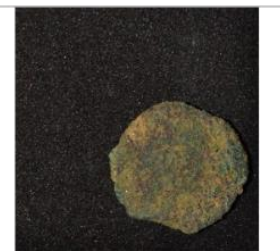

8892

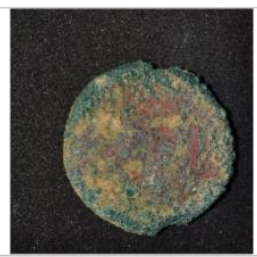

9883

Figure 1. Images of the 24 analysed artefacts from the Rakafot 54 archaeological site, labelled with their identifier code. Each photograph represents an area of $3.5 \mathrm{~cm} \times 3.5 \mathrm{~cm}$. 
corrosion products. Figure 1 shows the high-resolution images of the artefacts and their identifier codes.

Under visual observation, most of the artefacts appeared to be covered by a thick layer of corrosion products that were rather non-uniform. Brownish or dark-green patinas were predominantly present on the surface, while some areas had a light-green colour; soil traces were also found on the surface.

\subsection{Raman spectroscopy}

Superficial corrosion products were analysed using Raman spectroscopy, a technique widely used in the characterisation of metallic artefacts. Measurements were performed using the BWTEK i-Raman Plus spectrometer. This is a portable instrument equipped with an optical-fibre probe to analyse specific areas of the sample and a high quantum efficiency CCD array detector to guarantee a good signal-to-noise ratio in the acquired spectra. A laser wavelength of $532 \mathrm{~nm}$ was used for all measurements, which were carried out in the range between 150 $\mathrm{cm}^{-1}$ and $4,200 \mathrm{~cm}^{-1}$ with a resolution of $7.3 \mathrm{~cm}^{-1}$. After optimising the measurement parameters on reference samples, as described in [17], spectra were acquired using a laser power of 6 $\mathrm{mW}$, with 10 repetitions and an integration time of $20 \mathrm{~s}$, in order to avoid any modification or degradation being induced in the material by the laser radiation.

As the samples under study were not flat but had irregular shapes and high surface roughness, measurements were carried out by gradually changing the distance between the probe and the analysed artefact to focus the laser beam and have the best signal-to-noise ratio in the acquired spectrum.

\subsection{Data analysis}

PCA was used to recognise the different patterns present in the acquired Raman spectra and to support the identification of corrosion products on the samples. PCA is a powerful tool that allows the reduction of the dimensionality of a dataset, keeping only those variables that account primarily for data variance [18]. Thus, it transposes all the vectors representing each of the acquired spectra into a new space that has a dimension equal to the number of significant components evaluated through PCA. In matrix notation, it is possible to express the original spectra as follows:

$$
X=T \cdot P^{T}+E,
$$

where, if we have $I$ samples and $J$ points for each measurement, $X$ is the original data matrix (with a dimension of $I x J$ ), $P$ is the loading matrix (with a dimension of $J \times K$, where $K$ is the number of significant components), which form the eigenvectors representing the new space, $T$ is the score matrix (with a dimension of $I \times K$ ), which form the eigenvalues derived from the $X$ matrix decomposition, and $E$ is the residual matrix, also known as the error matrix, which contains the variance burden not explained by the PCA model [19].

In the present study, PC analysis was carried out on the acquired Raman spectra using a Python script. First, preprocessing was performed, as is usually required for this kind of data [20]. The analysed spectrum was limited to the interval of interest between $150 \mathrm{~cm}^{-1}$ and $1,150 \mathrm{~cm}^{-1}$, where the peaks related to the copper corrosion products are present [21]. Baseline removal was performed using asymmetric least square smoothing, as described in [22]. A Savitzky-Golay filter was then applied [23] using the savgol_filter function from the SciPy library [24]; the original spectrum was processed using a window length of $15 \mathrm{~cm}^{-1}$ and fitted with a $2^{\text {nd }}$ order polynomial. After that, standard normal variate transformation was performed [25] using the following calculation for each measurement point:

$$
y_{S N V}=\frac{y-\bar{y}}{s t d},
$$

where $y_{S N V}$ is the variable value after transformation, $y$ is the original variable, $\bar{y}$ is the mean value in the original spectrum and std is the standard deviation.

The results of the pre-processing operations can be seen in Figure 2, where the results obtained for one of the spectra is presented. As can be seen, only the wavenumber range from 150 $\mathrm{cm}^{-1}$ to $1,150 \mathrm{~cm}^{-1}$ is selected. The broad background caused by fluorescence is then removed, the spectrum is filtered to improve the signal-to-noise ratio and, finally, normalisation is performed.

Original data matrix decomposition was performed using the PCA package from the sklearn.decomposition module [26]; in this way, eigenvectors and scores are directly computed. The PCA model was improved by eliminating possible outliers, which generally proved to be noisy measurements, considering two parameters, leverage and root mean square deviation (RMSD). The former is defined as the diagonals of the 'hat matrix' $\mathrm{H}$ :

$$
H=T\left(T^{T} T\right)^{-1} T^{T},
$$

where $T$ is again the score matrix. All measurements with a leverage higher than three times the median value were discarded from the model construction and analysed separately [27]. Moreover, RMSD, which quantifies the difference between the acquired spectrum and the same spectrum reproduced by the PC model, was calculated as follows:

$$
R M S D=\sqrt{\frac{\sum_{i=1}^{J}\left(X-T P^{T}\right)^{2}}{J}},
$$

where $J$ is the number of points for each measurement, $X$ is the original data matrix, $T$ is the score matrix and $P$ is the loading matrix. Model optimisation was carried out until all the reproduced spectra had an RMSD lower than $30 \%$ of the initial standard deviation.

After applying the obtained PCA model to the spectra, it was possible to compute the scores related to the most important components. Similarity between spectra was evaluated using
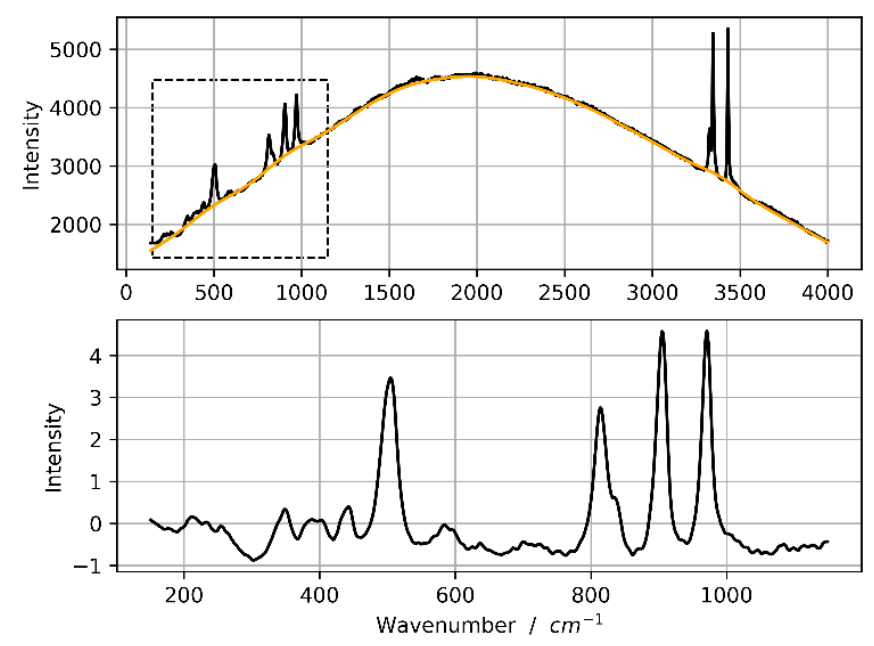

Figure 2. Top: original Raman spectrum acquired on sample 9883 . Bottom: same spectrum in the restricted range of interest between $150 \mathrm{~cm}^{-1}$ and $1,150 \mathrm{~cm}^{-1}$ after pre-processing and normalisation. The yellow line represents the computed baseline in the original spectrum. 


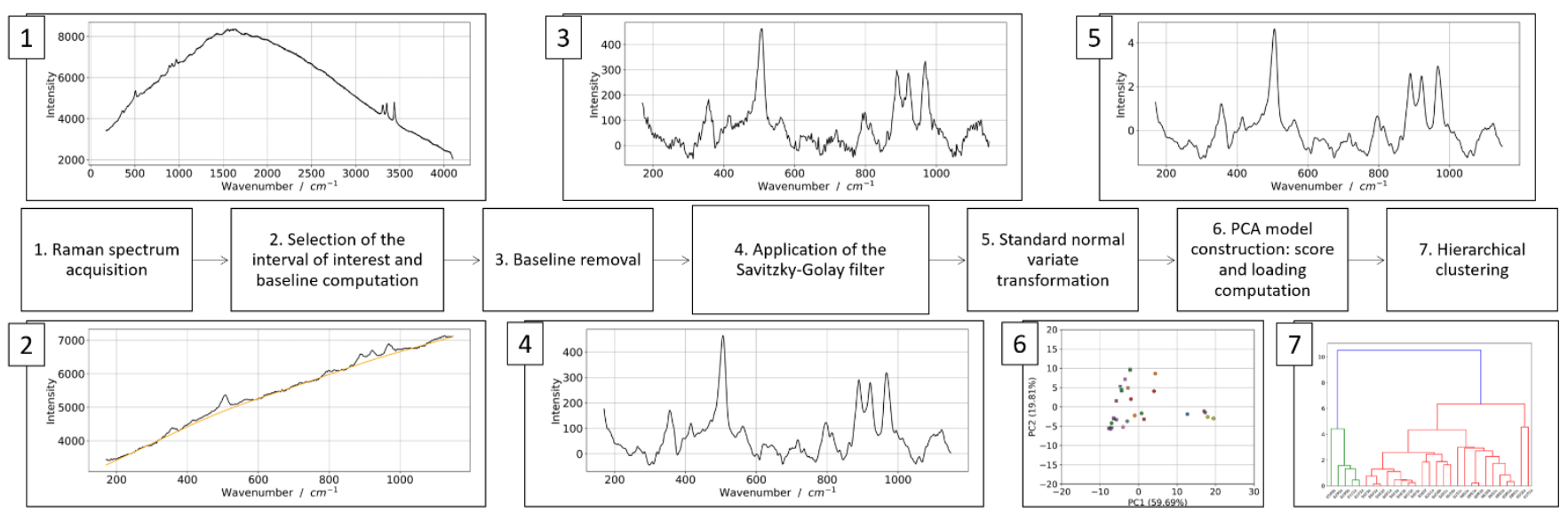

Figure 3. Flow-chart summarising the steps involved in PCA processing.

hierarchical clustering. This analysis was performed using the Agglomerative clustering method in the sklearn.cluster module; Euclidean metric was used to compute the linkage. In Figure 3, a flow chart summarises the steps involved in PCA processing.

\section{RESULTS AND DISCUSSION}

A preliminary study by Peters et al. [28] analysed the chemical composition of the artefacts under investigation by means of $\mathrm{X}$ ray fluorescence. This study revealed that most of the artefacts were produced from a copper-lead-tin alloy, with a lead content that, in some cases, reached $14 \mathrm{wt} \%$. Starting from this basis, the present investigation tried to identify the specific corrosion products that characterise the artefacts by means of Raman spectroscopy.

Gentle brushing without any solvent, to avoid surface modification or the dissolution of the corrosion products, was the only cleaning operation that was performed before the Raman measurements were taken, as soil traces can affect their acquisition by causing large fluorescence signals in the spectrum.

The acquisition of Raman spectra was not straightforward, as the shape and conservation state of the artefacts were not optimal. As mentioned above, due to the irregular shape, the focusing of the laser beam was performed by manually adjusting the distance between the spectrophotometer probe and the sample in order to achieve optimal conditions. Moreover, despite the preliminary cleaning, soil traces caused a broad fluorescence signal in the central part of the spectrum, between $1,200 \mathrm{~cm}^{-1}$ and $3,000 \mathrm{~cm}^{-1}$, as can be seen in Figure 2 for sample 9883. A good signal-to-noise ratio could be obtained only when brightgreen patinas were analysed, while measurements could not be performed on the brownish patinas, possibly associated with cuprite [28]. This could be due to the low thickness of these layers or to the excitation wavelength that was used in this study; only a $532 \mathrm{~nm}$ laser light was employed.

For all 24 artefacts, at least five Raman spectra were acquired for different areas, and in all cases, it was possible to find at least one area giving a good Raman signal.

Taking into account the characteristic peaks for copper corrosion products [21], the analysis was limited to the wavenumber range between $150 \mathrm{~cm}^{-1}$ and $1,150 \mathrm{~cm}^{-1}$. After performing the pre-processing operations, as described in Section 2.3, the resulting spectrum appears as shown in Figure 2 for sample 9883. From a visual comparison of the different measurements, it was possible to distinguish two patterns that were predominant in most of the spectra. The first was characterised by four intense peaks at $505 \mathrm{~cm}^{-1}, 814 \mathrm{~cm}^{-1}, 905$ $\mathrm{cm}^{-1}$ and $972 \mathrm{~cm}^{-1}$, with the peak at $814 \mathrm{~cm}^{-1}$ having a shoulder at a higher wavelength. The second pattern exhibited an intense peak at $505 \mathrm{~cm}^{-1}$ and then another four, respectively, at 796 $\mathrm{cm}^{-1}, 888 \mathrm{~cm}^{-1}, 921 \mathrm{~cm}^{-1}$ and $967 \mathrm{~cm}^{-1}$. These two patterns could be associated with the characteristic spectra of two copper hydroxy-chlorides $\left(\mathrm{Cu}_{2} \mathrm{Cl}(\mathrm{OH})_{3}\right)$, atacamite and its polymorph, clinoatacamite.

Due to the presence of several minor peaks and the noise related to the non-ideal acquisition conditions, data were processed also using PCA, an unsupervised multivariate analysis. Using this chemometric technique, it is possible to classify different measurements, identifying their characteristic patterns. The PCA model was built progressively, removing those spectra that were identified as outliers by the algorithm (see Section 2.3 for further details on outlier detection). All these measurements had been previously classified as noisy acquisitions, and some of them were dubiously identified as atacamite. After model optimisation, all measurements fell into the desired leverage and RMSD range (leverage below three times the median value and RMSD lower than $30 \%$ of the initial variance).

The cumulative explained variance trend can be observed in Figure 4. The first three components represent an overall variance of about $85.5 \%$ - respectively, $59.7 \%, 19.8 \%$ and $6.0 \%$, which is a satisfactory level. Taking also into account that the fourth component captures only $4.2 \%$ of the total variance, it

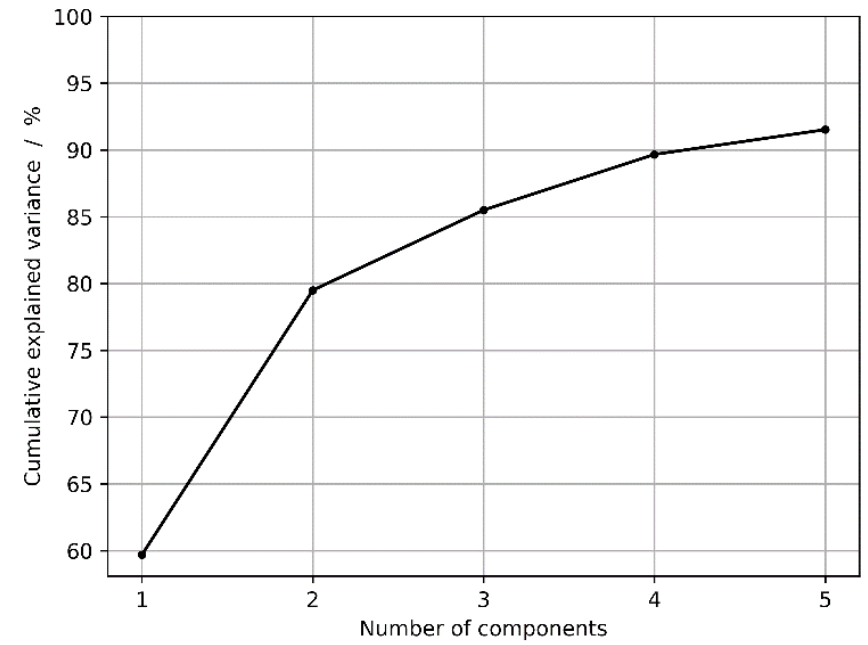

Figure 4. Cumulative explained variance for the first five components, as obtained from the PCA model. 

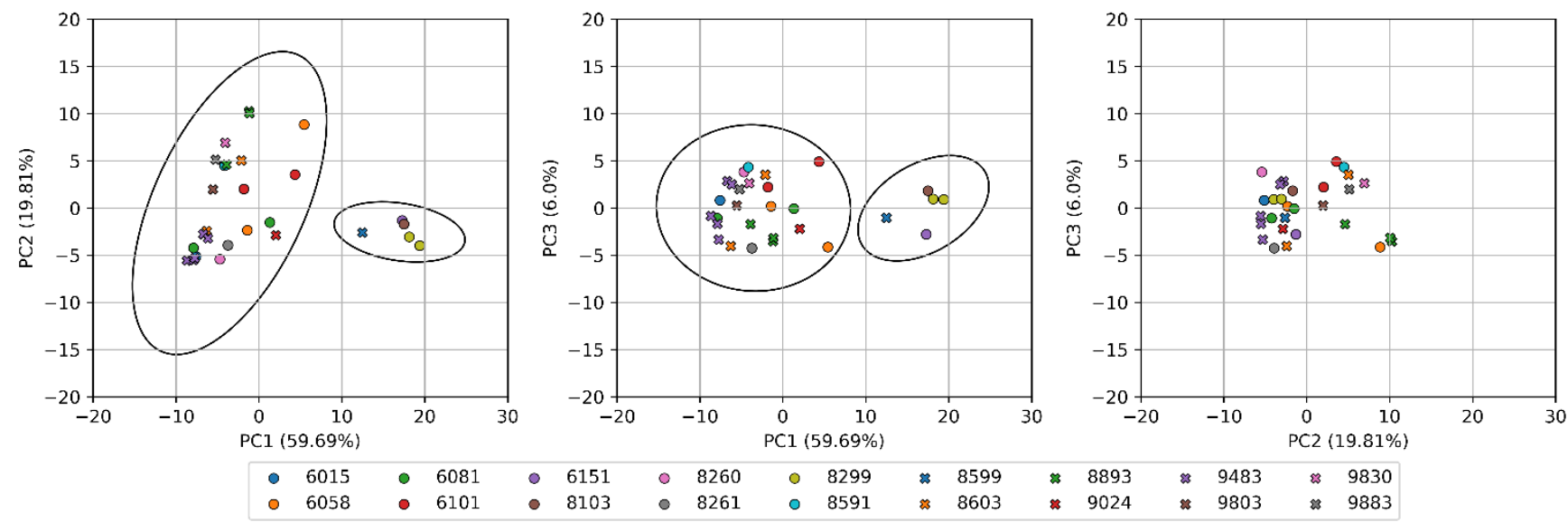

Figure 5. Score plots of the first three components (PC1-PC2, PC1-PC3 and PC2-PC3). Percent variance captured by each PC is reported in parenthesis along each axis.

was decided to use only the first three components to carry out the analysis. Using components representing a low percentage of the initial variance can have adverse effects because they would generally fit the measurement noise and not the important parts of the spectrum.

The result of the PC analysis is presented in Figure 5, which plots the scores of the three principal components two at a time; spectra that appear close in these graphs are similar to each other. As can be seen, measurements group together in two clusters, and the main discriminant is the PC1 score value, which is positive in one case and negative or with low positive values in the other. This behaviour is clearly visible in the PC1-PC2 and PC1-PC3 plots, while cluster formation is not evident in the PC2PC3 plot. Four samples belong to the first group, namely 6151, 8103, 8299 and 8599, while 6015, 6058, 6081, 6101, 8260, 8261, $8591,8603,8893,9024,9483,9803,9830$ and 9883 are part of the second. The absence of clusters in the PC2-PC3 plot can be explained by considering the low variance captured by the third component (only 6.0\%) and the PC3-loading trend (Figure 6). In fact, this plot does not contain many significant features, only a peak at about $977 \mathrm{~cm}^{-1}$, which can be found in the atacamite spectrum, and a minimum in the region around $198 \mathrm{~cm}^{-1}$. Presumably, this component is used in the model in linear
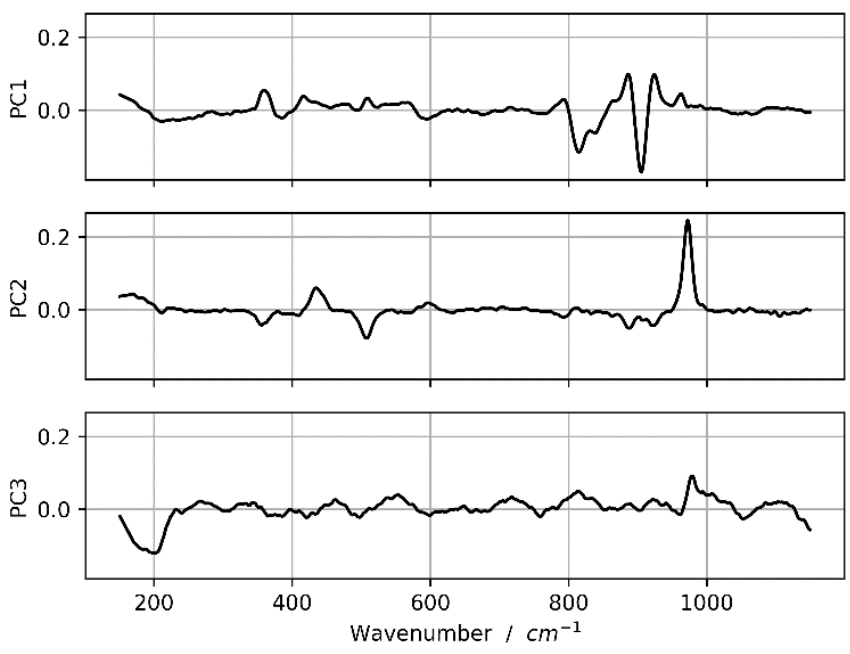

Figure 6. Loadings associated with the first three components in PCA. combination with the main two components only to improve the fitting of the most important peaks found in the other two components.

The reason for the discrimination in separated clusters can be found by looking at the loadings associated with the first two components (Figure 6). In the PC1 loading, peaks associated with atacamite $\left(811 \mathrm{~cm}^{-1}\right.$ and $\left.904 \mathrm{~cm}^{-1}\right)$ are in the negative range, so a negative score is needed in order to fit the original spectrum. At the same time, peaks associated with clinoatacamite (for example, at $884 \mathrm{~cm}^{-1}$ ) are in the positive range. PC2 loading exhibits a different trend; here, it is possible to find a peak in the negative range $\left(506 \mathrm{~cm}^{-1}\right)$, which can be seen both in the atacamite and clinoatacamite spectrum. However, peaks associated with clinoatacamite $\left(885 \mathrm{~cm}^{-1}\right.$ and $\left.922 \mathrm{~cm}^{-1}\right)$ are in the negative range, thus justifying the reason for the negative scores in the samples of the first group, and an intense peak at $970 \mathrm{~cm}^{-1}$ associated with atacamite is present. Therefore, the attribution of both positive and negative scores for atacamite samples in the second component can be explained by their features being in both ranges. Moreover, in samples with a negative PC2 score, the feature at around $970 \mathrm{~cm}^{-1}$ in the original spectrum can be reproduced by peaks at $962 \mathrm{~cm}^{-1}$ and $977 \mathrm{~cm}^{-1}$ in the PC1 and PC3 loading. The goodness of fit for the two example spectra can be evaluated by looking at Figure 7: on top, a spectrum identified as atacamite is presented, while at the bottom, one associated with clinoatacamite is shown. The yellow line, representing the model, was computed as the product between the scores and the loading matrix:

$$
X_{M O D}=T \cdot P^{T} \text {. }
$$

It correctly fits the black dots that represent the measured spectrum. Notably, the most important peaks in both spectra are correctly fitted by the model, and the residual error is low in the whole range.

Thus, it is possible to state that the corrosion patina of the artefacts under study is mainly composed of copper hydroxychlorides, specifically atacamite and clinoatacamite. This agrees with the preliminary studies, which indicated the presence of chlorides in the excavation soil [28]. The presence of only two kinds of corrosion product suggests the existence of quite uniform conditions in the soil where the artefacts were buried, although, as discussed above, performing Raman spectroscopy with a different laser wavelength might reveal other compounds. 

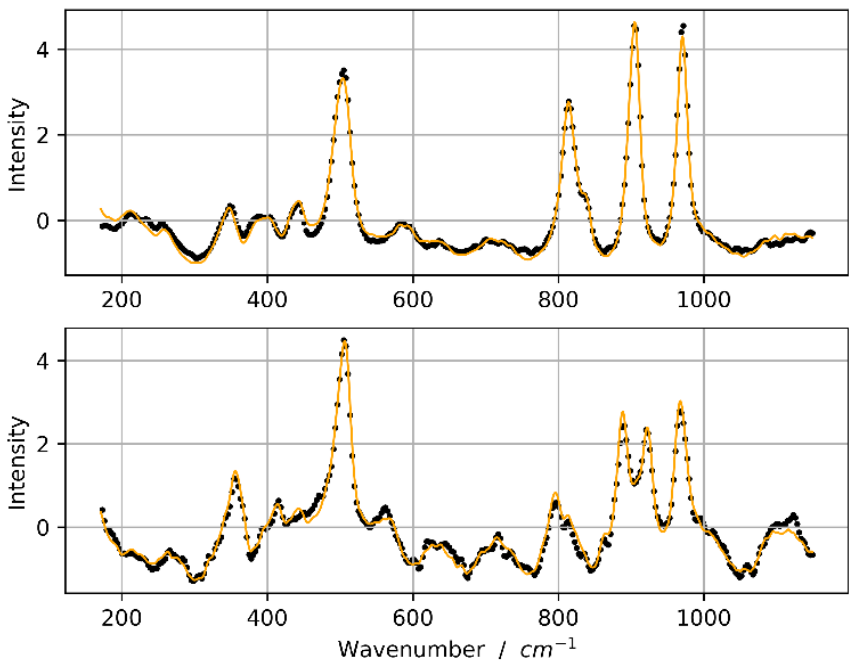

Figure 7. Top: sample 9883 (identified as atacamite). Bottom: sample 8103 (identified as clinoatacamite). Black dots are the measured spectra, while the result from the PCA model is represented by the yellow line.

Atacamite and its polymorph clinoatacamite are generally considered as the final product of copper corrosion in environments containing chlorides. First, a layer of cuprite $\left(\mathrm{Cu}_{2} \mathrm{O}\right)$ grows on the metal; then, in the presence of water and chloride ions, cuprous chloride is formed (nantokite, $\mathrm{CuCD}$ ), followed by copper hydroxychlorides. For this reason, conservation conditions of the investigated artefacts can be considered quite stable, even if chlorides are present. Finally, the morphology of the grown patina should also be taken in account. Only if this layer is sufficiently dense and continuous can it hinder the diffusion of the reactive compounds, otherwise the cyclic reactions related to copper corrosion would continue until the mineralisation of the metal is complete.

\section{CONCLUSIONS}

A non-invasive characterisation of bronze artefacts was carried out using Raman spectroscopy. Using multivariate analysis (PCA), it was possible to identify the main corrosion products present in the artefacts' patina, namely atacamite and clinoatacamite. These results, coupled with the information from the soil characterisation, provides a deeper insight into the artefacts' corrosion processes that occur during long-term exposure in a predominantly dry environment containing chlorides. Moreover, they can be used by restorers and conservators to define the most appropriate restoration strategy for these artefacts.

\section{ACKNOWLEDGEMENT}

This research was performed in the frame of a Joint Project for the Internationalisation of Research between Politecnico di Torino (Italy) and the Ben Gurion University of the Negev, (Israel). It was financially supported by Compagnia di San Paolo (Torino, Italy) in 2019.

\section{REFERENCES}

[1] A. G. Nord, E. Mattsson, K. Tronner, Factors influencing the long-term corrosion of bronze artefacts in soil, Protection of Metals 41 (2005), pp. 309-316. DOI: $10.1007 /$ s11124-005-0045-9
[2] M. C. Bernard, S. Joiret, Understanding corrosion of ancient metals for the conservation of cultural heritage, Electrochimica Acta 54 (2009), pp. 5199-5205.

DOI: $10.1016 /$ i.electacta.2009.01.036

[3] D. Scott, Bronze disease: a review of some chemical problems and the role of relative humidity, Journal of the American Institute for Conservation 29 (1990), pp. 193-206. DOI: $10.1179 / 019713690806046064$

[4] L. Robbiola, J-M. Blengino, C. Fiaud, Morphology and mechanisms of formation of natural patinas on archaeological $\mathrm{Cu}$ Sn alloys, Corrosion Science 40 (1998), pp. 2083-2111. DOI: 10.1016/S0010-938X(98)00096-1

[5] R. Francis, The Corrosion of Copper and Its Alloys: A Practical Guide for Engineers, National Association of Corrosion Engineers, Houston, 2009, ISBN 9781575902257.

[6] P. Vandenabeele, H. G. M. Edwards, L. Moens, A decade of Raman spectroscopy in art and archaeology, Chemical Reviews 107 (2006), pp. 675-686. DOI: $10.1021 / \mathrm{cr} 068036 \mathrm{i}$

[7] O. Berger, P. B. Yersinc, J-B. Yersinc, C. Hartmannd, E. Hildbrand, V. Hubert, K. Hunger, M. Ramstein, M. Wörle, Applications of micro-Raman spectroscopy in cultural heritage examples from the laboratory for conservation research of the collections centre of the Swiss National Museums, Chimia 62 (2008), pp. 882-886.

DOI: $10.2533 /$ chimia.2008.882

[8] R. L. Frost, W. Martens, J. T. Kloprogge, P. A. Williams, Raman spectroscopy of the basic copper chloride minerals atacamite and paratacamite: implications for the study of copper, brass and bronze objects of archaeological significance, Journal of Raman Spectroscopy 33 (2002), pp. 801-806.

DOI: $10.1002 /$ irs. 921

[9] G. Bertolotti, D. Bersani, P. P. Lottici, M. Alesiani, T. Malcherek, J. Schlüter, Micro-Raman study of copper hydroxychlorides and other corrosion products of bronze samples mimicking archaeological coins, Analytical and Bioanalytical Chemistry 402 (2012), pp. 1451-1457. DOI: $10.1007 / \mathrm{s} 00216-011-5268-9$

[10] A. Inberg, D. Ashkenazi, M. Cohen, N. Iddan, D. Cvikel, Corrosion products and microstructure of copper alloy coins from the Byzantine-period Ma'agan Mikhael B shipwreck, Israel, Microchemical Journal 143 (2018), pp. 400-409. DOI: $10.1016 /$ j.microc.2018.08.033

[11] O. Papadopoulou, P. Vassiliou, S. Grassini, E. Angelini, V. Gouda, Soil-induced corrosion of ancient Roman brass - a case study, Materials and Corrosion 67 (2016), pp. 160-169. DOI: $10.1002 / \operatorname{maco} .201408115$

[12] M. Veneranda, J. Aramendia, O. Gomez, S. Fdez-Ortiz de Vallejuelo, L. Garcia, I. Garcia-Camino, K. Castro, A. Azkarate, J. M. Madariaga, Characterization of archaeometallurgical artefacts by means of portable Raman systems: corrosion mechanisms influenced by marine aerosol, Journal of Raman Spectroscopy 48 (2017), pp. 258-266.

DOI: $10.1002 /$ jrs. 4997

[13] L. Iannucci, J. F. Ríos-Rojas, E. Angelini, M. Parvis, S. Grassini, Electrochemical characterization of innovative hybrid coatings for metallic artefacts, EPJ Plus 133 (2018), pp. 1-7. DOI: $10.1140 / \mathrm{epip} / \mathrm{i} 2018-12368-3$

[14] I. Marcaida, M. Maguregui, H. Morillas, N. Prieto-Taboada, M. Veneranda, S. Fdez-Ortiz de Vallejuelo, A. Martellone, B. De Nigris, M. Osanna, J. M. Madariaga, In situ non-invasive multianalytical methodology to characterize mosaic tesserae from the House of Gilded Cupids, Pompeii, Heritage Science 7 (2019), pp. 1-11. DOI: $10.1186 / \mathrm{s} 40494-019-0246-1$

[15] S. Carlesi, M. Ricci, C. Cucci, C. Lofrumento, M. Picollo, M. Becucci, Multivariate analysis of combined reflectance FT-NIR and micro-Raman spectra on oil-paint models, Microchemical Journal 124 (2016), pp. 703-711. DOI: $10.1016 /$ j.microc.2015.10.023 
[16] A. Sarmiento, M. Pérez-Alonso, M. Olivares, K. Castro, I. Martínez-Arkarazo, L. A. Fernández, J. M. Madariaga, Classification and identification of organic binding media in artworks by means of Fourier transform infrared spectroscopy and principal component analysis, Analytical and Bioanalytical Chemistry 399 (2011), pp. 3601-3611.

DOI: $\underline{10.1007 / \mathrm{s} 00216-011-4677-0}$

[17] L. Es Sebar, L. Iannucci, Y. Goren, P. Fabian, E. Angelini, S. Grassini, Non-invasive characterization of ancient $\mathrm{Cu}$-based coins using Raman spectroscopy, Proc. of 2019 IMEKO TC4 International Conference on Metrology for Archaeology and Cultural Heritage, Florence, Italy, 4 - 6 December 2019, pp. 389394. Online [Accessed 26 March 2021] https://www.imeko.org/publications/tc4-Archaeo2019/IMEKO-TC4-METROARCHAEO-2019-77.pdf

[18] J. N. Miller, J. C. Miller, Statistics and Chemometrics for Analytical Chemistry, Pearson, Harlow, 2010, ISBN 978-0-273-73042-2.

[19] K. Kumar, Principal component analysis: most favourite tool in chemometrics, Resonance 22 (2017), pp. 747-759. DOI: $10.1007 / \mathrm{s} 12045-017-0523-9$

[20] P. Gemperline, Practical Guide to Chemometrics, CRC Press, Boca Raton, 2006, ISBN 1-57444-783-1.

[21] R. L. Frost, Raman spectroscopy of selected copper minerals of significance in corrosion, Spectrochimica Acta Part A 59 (2003), pp. 1195-1204 DOI: $10.1016 / \mathrm{S} 1386-1425(02) 00315-3$

[22] P. H. C. Eilers, H. F. M. Boelens, Baseline correction with asymmetric least squares smoothing, Leiden University Medical Centre report, 2005

[23] A. Savitzky, M. J. E. Golay, Smoothing and differentiation of data by simplified least squares procedures, Analytical Chemistry 36 (1964), pp. 1627-1639. DOI: $10.1021 / \mathrm{ac} 60214 \mathrm{a} 047$

[24] P. Virtanen, R. Gommers, T. E. Oliphant, M. Haberland, T. Reddy, D. Cournapeau, E. Burovski, P. Peterson, W. Weckesser,
J. Bright, S. J. van der Walt, M. Brett, J. Wilson, K. J. Millman, N. Mayorov, A. R. J. Nelson, E. Jones, R. Kern, E. Larson, C J Carey, İ. Polat, Y. Feng, E. W. Moore, J. VanderPlas, D. Laxalde, J. Perktold, R. Cimrman, I. Henriksen, E. A. Quintero, C. R. Harris, A. M. Archibald, A. H. Ribeiro, F. Pedregosa, P. van Mulbregt, SciPy 1.0: fundamental algorithms for scientific computing in Python, Nature Methods 17 (2020), pp. 261-272.

DOI: $10.1038 / \mathrm{s} 41592-019-0686-2$

[25] R. J. Barnes, M. S. Dhanoa, S. J. Lister, Standard normal variate transformation and de-trending of near-infrared diffuse reflectance spectra, Applied Spectroscopy 43 (1989), pp. 772-777. DOI: $\underline{10.1366 / 0003702894202201}$

[26] F. Pedregosa, G. Varoquaux, A. Gramfort, V. Michel, B. Thirion, O. Grisel, M. Blondel, P. Prettenhofer, R. Weiss, V. Dubourg, J. Vanderplas, A. Passos, D. Cournapeau, M. Brucher, M. Perrot, É. Duchesnay, Scikit-learn: Machine learning in Python, Journal of Machine Learning Research 12 (2011), pp. 2825-2830. Online [Accessed 24 March 2021] https://imlr.csail.mit.edu/papers/volume12/pedregosa11a/pedr egosa11a.pdf

[27] A. F. Mejia, M. B. Nebel, A. Eloyan, B. Caffo, M. A. Lindquist, PCA leverage: outlier detection for high-dimensional functional magnetic resonance imaging data, Biostatistics 18 (2017), pp. 521536.

DOI: $10.1093 /$ biostatistics/kxw050

[28] M. H. J. Peters, Y. Goren, P. Fabian, J. Mirao, S. Grassini, E. Angelini, Characterisation of Roman copper alloy artefacts and soil from Rakafot 54 (Beer Sheva, Israel), Proc. of 2019 IMEKO TC4 International Conference on Metrology for Archaeology and Cultural Heritage, Florence, Italy, 4 - 6 December 2019, pp. 395400. Online [Accessed 26 March 2021] https://www.imeko.org/publications/tc4-Archaeo2019/IMEKO-TC4-METROARCHAEO-2019-78.pdf 